rolling-stock to the highest pitch ; his engines are patterns to be used with advantage, and their coal consumption is the lowest on record. Chapter IX. describes the SouthEastern and Chatham Railways ; and the volume concludes with Chapter X., on the Great Eastern Railway. These last chapters lack none of the interest to be found in the earlier ones in the book.

The second volume, on Scottish railways, is merely a continuation of the first, and is written in the same lucid style. Its most interesting part is a description of the Forth Bridge. Mr. Acworth gives a good account of the bridge and the earlier schemes proposed for crossing the Forth.

Mr. Acworth has written two most interesting books, which will be of great use to all in any way connected with, or interested in, the British railway system.

N. J. L.

\section{DISEASES OF PLANTS}

Diseases of Plants. By Prof. H. Marshall Ward, F.R.S., M.A. (London: Society for Promoting Christian Knowledge.)

T IS little book is an excellent popular introduction to the study of the diseases of plants, in so far as they are due to the attacks of parasitic Fungi or similar organisms. The author, who has made this field of research especially his own, succeeds in being intelligible and interesting to ordinary readers, without in any degree sacrificing the scientific character of his work.

The book is illustrated by fifty-three woodcuts, which have been very well selected, many of them from the author's own papers. In certain cases, however, the engraving leaves something to be desired, and scarcely does justice to the original figures.

An introductory chapter explains what is here meant by disease in plants, namely "those disturbances of the structure and functions of the plant, which actually threaten the life of the plants, or at least their existence as useful objects of culture." The two factors of disease, the external cause on the one hand, and the condition of the patient on the other, are clearly distinguished.

The second chapter gives a general account of Fungi as saprophytes and parasites. Mucor is described as an example of the former, and vine-mildew (Peronospora viticola) of the latter group.

The succeeding nine chapters, forming the bulk of the book, are occupied with the consideration of special diseases.

First comes the "damping-off" of seedlings, a disease only too well known to gardeners, due to the attacks of various species of Pythium. The whole life-history of the parasite is described. In Fig. 9 it is a pity that the point of attachment of the antheridium is not more clearly shown.

Next, we have an account of the very interesting disease of cabbages and other Crucifers, known as "fingers and toes," "club-root," \&c. Here the cause of the mischief is a Myxomycete, and this is the only case of a non-fungoid disease described in the book. Happily, a satisfactory cure can here be prescribed.
Chap. v. is on the potato-disease. An account of the normal mode of nutrition of the plant in health is introduced in order to show the exact nature of the deadly injury which is wrought by the Phytophthora. As a preventive measure, the selection of resistant varieties of the potato is especially recommended. Chap. vi. is devoted to the "smut" of corn. The cause of the frequent failure of protective dressings applied to the ripe grain is discussed. If, however, as Jensen believes, the ovule may be infected at the time of flowering, an altogether new light is thrown on this question.

After a chapter on the disease known as "bladderplums," caused by the yeast-like Fungus Exoascus, we come to the lily-disease. The Fungus which is here responsible has been shown by Prof. Ward to afford an excellent example of a saprophyte which can become a parasite on occasion.

The next three chapters describe the ergot of rye, the mildew of hop (Podosphæra), and the rust of wheat. In the case of the hop-disease, a figure of the conidia might have been added with advantage. The now familiar but always interesting story of the heterœcism of rust is well told.

With a caution which in the case of a popular work cannot be too highly commended, the author avoids expressing any opinion on the subjects of fertilization in Podosphæra, and of the function of the spermogonia in Æcidium.

In the concluding chapter, Prof. Ward endeavours to interest his readers in the wider questions of mycology, so fascinating to the botanist, such as the phylogenetic origin and relationships of the Fungi.

The book should have a wide circulation among the numerous classes interested in the important group of diseases of plants with which it deals.

D. H. S.

\section{OUR BOOK SHELF.}

The Physician as Naturalist. Addresses and Memoirs bearing on the History of and Progress of Medicine chiefly during the last hundred years. By W. T. Gairdner, M.D. (Glasgow: Maclehose and Sons, 1889.)

A sUCCESSFul physician, during a long and busy life, is frequently called upon to preside and deliver addresses at meetings at which he is expected to treat his subjects in a more or less popular manner.

Dr. Gairdner has brought together a most interesting series of such addresses, which fall into two main groups. First, those in which he has contrasted the treatment of the present day with that in vogue among our predecessors of more or less remote times; and in which he has attempted to present the answer to that everinteresting question, "Is the treatment of disease adopted at the present day superior to that in vogue formerly? And if so, in what does its superiority consist? " Second, those in which he lays down the lines on which he considers the medical education of the future should be conducted. in order to lead to still greater advances.

The dependence of modern treatment upon the discussion of accumulations of facts, and not solely upon theory, and the necessity of making experience and 